Understanding inclusion in teacher education - A view from student teachers in England

Dr Jane Essex (corresponding author), University of Strathclyde, UK ORCID identifier: 0000-0002-9938-8134

Email: Jane.essex@strath.ac.uk

Twitter:@jane essex

Professor Nafsika Alexiadou, Umeå University, Sweden

ORCID identifier: 0000-0002-8731-4728

Email: nafsika.alexiadou@umu.se

Dr Paula Zwozdiak-Myers, Brunel University London, UK

ORCID identifier: 0000-0001-7860-2261

Email:paula.zwozdiak-myers@brunel.ac.uk 


\section{Understanding inclusion in teacher education - A view from student teachers in England}

\section{Introduction}

The concept of inclusion has been widely accepted and integrated as a core objective for schools and teacher education programs around the world (UNESCO, 2009; EASNIE, 2018). But, despite 25 years of debates on inclusion, there are still different conceptualisations of what inclusion means (Ainscow et al. 2006) and different understandings of its objectives by schools, by researchers, and in policy (Allan, 2010; Waitoller and Artiles, 2013). As a result, there is a lack of consensus on the best ways to achieve it (Smyth et al., 2014; Sosu et al., 2010).

Within English teacher education the requirements for inclusion are primarily defined in the Department for Education (DfE, 2011) Teachers' Standards document that outlines the criteria for the qualification of new teachers; and, in the inspection framework that regulates initial teacher education courses that follow the Standards (Ofsted, 2015). Teachers are expected to meet the needs of pupils, 'primarily those at risk of underachievement' and these are identified along the lines of 'special educational needs', 'high ability', 'disability' and having 'English as an additional language' (DfE, 2011:12; Ofsted, 2015:38). In addition to defining inclusion along the lines of achievement and ability, a new form of inclusion that links to culture was introduced through the 'Prevent Strategy'. The Strategy was published by the UK government in 2011 and became a legal duty for public sector institutions in 2015 (Home Office, 2019). It has a much wider remit than education, but within schools it aims to promote 'fundamental British values', tasking teachers with the responsibility to detect 'pupils at risk of radicalisation' and to refer them to appropriate authorities (DfE, 2011).

This widening of official definitions of inclusion has had serious implications for teacher education and the preparation of student teachers to understand inclusion and embed it in their practice. Teacher education faces competing expectations (Ben-Peretz and Flores, 2018) and is called to improve the overall quality of instruction in highly differentiated school environments, to raise all pupils' educational outcomes, address multicultural classrooms and children with special needs, while at the same time meet accountability pressures in an increasingly neo-liberal policy context driven by performativity objectives (Artiles and Dyson, 2005; Furlong, 2013). In such contexts, the policy parameters and the official views of what counts as good quality teaching and pedagogy very much frame the nature of inclusion that is possible within schools. Practicing inclusive teaching in schools that operate on the basis of non-inclusive principles leads to ambiguity and the experience of tensions for student teachers (Cochran-Smith, 2004; DeLuca, 2012; Gavish, 2017). Not surprisingly, international research suggests that newly qualified teachers do not feel well prepared for dealing with the diversity of classrooms, and inclusion seems to be a particularly difficult pedagogical objective to achieve (Schmidt et al., 2015; Walton and Lloyd, 2012).

In this paper we explore the ways in which student teachers understand and practice inclusion during the final stages of their training, and present findings from two studies with University 
teacher-education providers in England. In particular our research looks at: (i) the ways in which student teachers conceptualise inclusive practice and discuss its implications for their work; (ii) the student teachers' perceptions of the fundamental British values framework (FBV) and the wider Prevent Strategy in relation to inclusion; and (iii) the opportunities and tensions student teachers identify in their practice, and how they address them.

In the first part of the paper we discuss the concept of inclusion and its various interpretations within schools and teacher education. We also discuss the significance of policy frameworks that are necessary to support an inclusive education, and we present our theoretical position in relation to these two areas. In the following two sections, we present our methodology and empirical findings of the research. Finally, we discuss the implications of our research for teacher education.

\section{Inclusive education and the nature of policy}

In a systematic review of the concept of inclusion, Göransson and Nilholm (2014) have identified four distinct concepts used in education research: (a) definitions of inclusion that centre around the physical placement of pupils with special needs in mainstream classrooms; (b) individually-focused inclusion to meet the academic and social needs of disabled pupils; (c) inclusion aimed at meeting the needs of all pupils; and, (d) inclusion for building community in schools and classrooms. The authors aptly conclude that "definitional problems indicate differences in beliefs about what schools can and should accomplish" (ibid: 275), a fundamentally political issue that relates to the overall goals of schooling systems. We take this as our beginning premise, since we follow a critical approach to our analysis of inclusion, how it is understood and enacted in classroom settings, seeking to examine the embedded ideological assumptions it entails (Kellner, 2003). Such assumptions relate to theoretical understanding of pupils' learning, but also knowledge and understanding of the social contexts that shape the experiences of children (Florian and Spratt, 2013; Gay, 2010). It is these theoretical premises that guide different types of pedagogy, but are also strongly shaped by policy frameworks that steer the system towards high achievement - seen as dissociated from inclusion concerns in several research studies (Gilroy, 2014).

Policy and practice within teacher education in England reflect all four conceptions of inclusion described by Göransson and Nilholm (2014), combining ability-based models (and the targeting of pupils seen as 'at risk') with more pluralist notions of inclusion seeking to meet the needs of all learners (Ainscow et al., 2006; UNESCO, 2009). This has led to a system trying to optimise educational attainment for the entire population of students, while also expanding the pupil categories that need to receive special attention, and in the process generating what Skidmore (1996) called a typology of educational vulnerability.

Views of inclusion as primarily related to ability are strongly represented within English teacher education policy and the inspectorate, and give rise to official guidance for categorising pupils according to assessments of their academic or social need (where the 'social' is seen to impede academic performance). Despite the academic arguments and 
research against over-reliance on such practices (Gavish, 2017; Robinson and Goodey, 2018), they are widely used in ITE as well within schools. Manifestations of such practices are found in strategies for minimising under-attainment, some more 'inclusive' than others: adjusting the curriculum (which can translate to a reduced curriculum for certain groups of pupils), providing targeted learning support, and deploying pedagogic approaches judged to be effective for all learners (Lambe and Bones, 2007); setting up separate 'inclusion units' for academic and disciplinary purposes, where pupils spend 'time out' of the normal classroom activities (Alexiadou and Essex, 2016); and the extensive practice of differentiating pupils on the basis of ability in different subject areas (Allday et al., 2013). In curriculum areas that are seen as selective or 'elitist', inclusion is further sacrificed to differentiation practices that imply responsibility for academic performance resting with individual pupils, and rarely leading to revisions of pedagogy to promote the inclusion of all pupils without compromising the content or learning objectives (Essex, 2018; Villanueva et al, 2012).

The implications of the use of such strategies for student teachers and their developing professional knowledge are important, especially when normalised in ITE courses and schools. They can embed a view that there are innate forms of ability that make different types of learning possible for different pupils, and hence restrict the potential for meaningful learning for all pupils. In the absence of critical perspectives, if strategies are adopted mechanistically, they restrict the curriculum and assessment possibilities for some of the more vulnerable students, and in effect contribute to exclusionary practices (Waitoller and Artiles, 2013).

A further and increasingly used notion of inclusion relates to questions of social justice, cultural diversity and difference. This corresponds most closely to the 'inclusion for building community' objective (Göransson and Nilholm, 2014), and ties in with UNESCO's (2009) definition of inclusion as a 'process aimed at offering quality education for all while respecting diversity and the different needs and abilities, characteristics and learning expectations of the students and communities, eliminating all forms of discrimination'. In an acknowledgement that schools and classrooms are increasingly diverse, ITE programs are expected to provide future teachers with a grounding on inclusive pedagogies that take into account different social contexts (especially linked to poverty) and cultures. In a critical social justice perspective, an inclusive pedagogy should challenge the hierarchical and exclusionary nature of schooling and aim at a radical transformation of the existing education practices since these are designed to marginalize or even fail particular categories of pupils (Cochran-Smith, 2004; Jones, 2016).

In the last few years, social disadvantage has been connected not only to poverty but also explicitly to ethnicity. Given heightened concerns about ethnic tensions and radicalization of young people, the Prevent Strategy requires all teachers and student teachers to uphold and promote 'fundamental British values, including democracy, the rule of law, individual liberty and mutual respect' and to be trained in the implementation of the government's counterterrorism strategy (DfE, 2014:5). The linking of inclusion to values is not new, and earlier versions of multicultural approaches performed somewhat similar functions, arguing that common expectations of all citizens is a unifying policy that furthers inclusion (Panjwani, 
2016). However, the strongly ideological basis of the Prevent Strategy and the surveillance environment it creates have seen a considerable backlash from schools, teachers and organisations that criticised it as discordant with the aspirations for inclusion (Elton-Chalcraft et al, 2017; Smith, 2016). In addition, the appropriation of liberal values and human rights as particularly British, is seen as partisan (Struthers, 2017) and to have produced school cultures that are 'simultaneously compliant and resistant' in following the letter but not the spirit of the guidance (Revell and Bryan, 2016: 351). Within teacher education, inclusive pedagogies that draw on cultural recognition and accommodation in diverse classrooms proves to be a difficult goal (Santoro and Forghani-Arani 2015). Research has for example, identified the paradox of the practice of 'othering' of cultures within teaching, in what was designed as a response to the need for multicultural teaching:

"The course team had to integrate the issue of diversity in all activities with the trainees. Predictably, this led to numerous examples of students using 'culture' in teaching sessions and coursework where naïve and essentialist representation of other cultures dominate" (in Alexiadou and Essex, 2016:10).

Such tensions between policy intensions and pedagogical practices reveal the often contradictory goals teacher education courses have to fulfil. The present education policy context, in which academic attainment is prioritised over other goals, has resulted in the adoption of multiple conceptions of inclusion that are often in tension (Ben-Peretz and Flores, 2018; Gilroy, 2014). In a climate of performativity drivers for classrooms and schools, reconciling inclusion and attainment becomes a choice between one/or the other - and the education quasi-market certainly provides financial and reputational incentives to schools for high attainment (Furlong, 2013; Gay, 2010). The strategies best suited for producing such attainment have led to the normalisation of pedagogic differentiation, helped by a fairly homogenous curriculum and assessment (Gomez, 2007), as well as a sharp rise in the exclusion of difficult pupils (DfE, 2018). Such a context impedes the development of inventive and innovative pedagogies, which are needed to meet the learning needs of diverse pupils (Young and Florian, 2013).

Despite ever more pressing policy drivers for inclusion, and the corresponding efforts of teacher educators, student teachers still struggle to implement inclusion in school. The literature reports the difficulties of supporting students in the use of the principles and theories of inclusion in both the university-led components of the course and in their placement school practice (Robinson and Goodey, 2018). Nevertheless, the concept of inclusion can be successfully integrated into initial teacher education programmes as a number of studies have shown (Young and Florian, 2013; Walton and Lloyd, 2012). This raises the possibility of training teachers who can act as agents of change, develop professional knowledge, and an ethic of practice for inclusion, and are capable of combining effective teaching, individualised instruction and intercultural education (Valiandes et al., 2018). In order to adjust ITE to such inclusive parameters, it is important to consider the beliefs of student teachers, and reinforce the importance of developing pupil-centred and critically reflexive practice in the classroom (Lancaster and Bain, 2018). 
Our research contributes to the debate around student teachers' understandings of inclusion, and the theoretical underpinnings they hold in relation to pupils' capacity for learning; the social contexts within which such learning takes place; and their own role in furthering their pupils' education horizons.

\section{The study}

The research reported in this article draws from two connected research studies that took place in the period 2011-2016. Both studies were constructed as case studies of preparing science teacher education students for inclusive practice, in two University-based Initial Teacher Education providers in England. The research is purely qualitative, draws on a social constructivist set of principles, and aims to access and understand the perspectives of research participants from within the context of their personal experiences and circumstances (Bryman, 2016). Our purpose was to gain an in-depth understanding of the student teachers' approach to and conceptualization of inclusion in all its complexity and (often) contradictory positions.

We were guided by our research questions and the view of inclusion as connected to educational, social and policy contexts that frame teacher education and pedagogic practice. These ideas about inclusion informed our discussions around fieldwork and the formulation of specific principles to guide the data collection. The ways in which student teachers speak and write about pupils and their learning, pedagogy and their own role in meeting their needs, reflect to a large extend their perceptions of what inclusion is. The theoretical knowledge they get from the ITE course, combined with the practical knowledge they are developing in classrooms and the official definitions of inclusion they have to apply, to a large degree shape these perceptions, even though of course individual student teachers bring their own interpretation of inclusion and, at times, challenge conventional thinking.

Our studies included policy and course material, surveys and interviews with teacher educators and student teachers (see, also Alexiadou and Essex, 2016). In this article we draw on the empirical material from student teachers that consists of: (a) interviews; (b) focus groups; and, (c) course assignments. In the first study, we conducted in-depth individual interviews with 17 science students during their Post-Graduate Certificate in Education $\left(\mathrm{PGCE}^{1}\right)$ course in a university in the north of England (we refer to them as Group A). These were students who did their teaching practice in schools serving mixed socio-economic population, with some schools in areas of high deprivation.

In the second study, we conducted focus groups and individual interviews with 14 science PGCE students in a different ITE provider (Group B), with most of the school placements in areas of very high ethnic diversity, with pockets of socio-economic deprivation. Some of the students in this study had also been able to undertake placements in Pupil Referral Units ${ }^{2}$,

\footnotetext{
${ }^{1}$ PGCE - a one-year course for graduates that train to become teachers in England. Successful completion of the course leads to Qualified Teacher Status (QTS), needed to teach in state schools.

${ }^{2}$ Pupil Referral Units are alternatives to mainstream school. Introduced in 1993, there are about 400 in England and Wales and they educate children who have been excluded from other schools -
} 
special schools, and a young offender's institution. Our interviews and focus groups with the student teachers in both studies explored their views on the meaning of inclusion and its underpinning educational and social assumptions, the possibilities and constraints in practising inclusion within science teaching, and their own role and needs in developing inclusive teaching.

Following permissions from the students, in the second study we also collected and analysed 32 'independent study tasks' (Group C) that all of the PGCE science students completed prior to the training they received on the Prevent Strategy (provided by a 'Prevent coordinator' in the local council). The independent study task asked students to describe and evaluate how the Prevent Strategy was implemented at their first placement school.

\section{The analysis of the data}

Our methodology followed an interpretive critical approach. We sought to understand how student teachers conceptualise inclusion in science teaching along with the conditions and contexts that shape their understanding and enactment of inclusion. The data (individual interview and focus group transcripts, and written assignments) were analysed through a combination of a thematic and discourse analysis (Alexiadou, 2001). At a first stage, we applied an inductive analytical approach where all texts were deconstructed and themes were derived that captured core meanings (Aronson, 1994). The characteristics and dimensions of each theme were subsequently described, defined, and superordinate thematic categories were identified in light of our research questions. The thematic categories refer to the students' (a) descriptions of pupils' learning and views on ability; (b) their evaluation of teaching strategies and practices in school placements and in their course; (c) inclusion as a pedagogical practice and in relation to wider social issues. These thematic categories are then further analysed not only in terms of their meaning, but also through a discursive lens, to identify the functions they perform in the text (Potter et al., 1993). In reviewing the analysed thematic categories, we ask questions such as: What do student teachers $d o$ with their talk? How do they select particular pedagogical examples to justify their practice? What normative statements do they use to promote particular views on inclusion? What aspects of inclusive teaching do they prioritise over others? What views of learning and knowledge do they value over others? At all stages of the analytical process, we tried to, 'give voice' to the student teachers and make sense of their understanding and pedagogic practice in relation to inclusion, and to do so as faithfully as possible to their intended meaning (Alexiadou, 2001).

We illustrate the process with an example: the theme 'respect for others' relates to descriptions of the social and educational contexts necessary for inclusion, as provided in student assignments and interviews. The theme has characteristics to do with perceptions of its universal value, its relational nature, and the particular conditions for developing it within classrooms. It links to other themes that are concerned with 'national values vs human rights', 'inclusive policy', and 'support structures'. 'Respect for others' is discursively used by some

usually for reasons related to disciplinary problems, but also special education needs. In 2017/18 there were about 16,700 pupils in such units (DfE, 2018b) 
students to justify compliance with the policy framework of the Prevent Strategy, whereas for others it provides justification for a quiet resistance to the Strategy by subsuming it under more universal liberal values. This theme is also used more theoretically to connect to views of inclusion that draw on core understandings of what teaching is needed for an inclusive and just society.

We present and discuss our findings below in relation to four emerging thematic areas that capture the student teachers' understanding and conceptualisation of inclusive practices in relation to: (a) pupils' learning and pedagogies of differentiation; (b) bridging university and school experiences; (c) the contradictions embedded in teacher education policy frameworks; and, (d) values and culture for an inclusive teacher education.

\section{Findings}

\section{Learning, ability, and pedagogies of differentiation}

The overwhelming majority of students in both our studies view inclusion as a positive concept in its abstract form. However, their responses and descriptions of their encounters with classrooms, pupils, and teaching practice, reveal conservative and conventional views of inclusion that define it primarily around (low) ability, and how it restricts knowledge and learning capacity. These conceptions then shape their pedagogical interventions. The connections between ability, learning and pedagogy are very strongly influenced by teaching arrangements in schools but also the policy texts that surround teacher education standards. In the Teacher Standards document, there is explicit instruction that teachers need to:

\section{Adapt teaching to respond to the strengths and needs of all pupils}

- Know when and how to differentiate appropriately, using approaches which enable pupils to be taught effectively (Department for Education, 2011:11)

In our study, whilst inclusion was in principle defined as ensuring maximum educational progress for all pupils, in specific pedagogic references it was seen as a mechanism for redressing perceived deficiencies in individual learners, an approach that aligns closely with the Equality Act's (2010) approach of defining 'protected characteristics'. Precisely because certain of the pupils in the school placements are expected (by their teachers) to underachieve in assessments, the practice of 'targeting' for teaching interventions is linked to both individual development, but also to the schools' performativity targets. This seemed to create difficulties for student teachers who struggled to draw boundaries and describe pupils in terms of who is 'educationally vulnerable', who is of 'low ability', and who has 'special educational needs' - usually associated with disability. Still, almost all student teachers find the principle of differentiating pupils by ability acceptable and necessary, justified by arguments that draw on 'fairness' (meeting individual pupils' needs), but also 'efficiency':

... (making) the teacher's job easier and I think it's fairer for the children. If you look at a mixed ability class, the slowest ones slow down the quickest ones and the 
quickest ones want to push it forward. So, I can think of no reason why you shouldn't set or stream. (Group A, interviewee A)

Even though inclusion as a wider academic process is valued in the literature (Ainscow, et al., 2006), student teachers continue to emphasise what they see as the 'price' for inclusion, specifically when inclusion is perceived as capping the opportunities for the high achieving pupils. This sense of compromise, between the rights of a few to achieve excellence and the needs and rights of less highly attaining learners has been noted previously (Gavish, 2017). Such views are common in our study and include misunderstandings that view inclusion as a zero-sum game where the inclusion of some leads to the disadvantage of others:

Inclusion shouldn't have to include everybody ... there should be a point where a person can't and shouldn't be included because it would be to the detriment to the rest of the group. (Group B, student teacher A)

Understandably, the student teachers are anxious to understand the practice of differentiated teaching. This however, means that practical issues of differentiating pupils and teaching materials take priority over a more reflective approach for meaningful learning. In this context, inclusion means redressing the perceived deficiencies of specific 'at risk groups' especially in the face of assessment pressures:

We had specific days in university on different groups of learners. I had never thought before about a lesson plan for each specific group. (Group B, student teacher L)

I am not able to differentiate well for Autistic Spectrum Disorder because I haven't had much experience of it. (Group B, student teacher S)

There was, nevertheless, recognition of pupils' individuality, and hence the limitations and potential dangers of categorising them in uniform terms: "'Here is the autistic group'... but they're completely different to each other!" (Group B, student teacher C).

When it comes to designing teaching strategies for differentiated teaching, we found an alarming lack of awareness that this leads to a reduced view of knowledge potential for the weaker pupils, and to a restricted curriculum. The notion of 'ability as a fixed quality' and related labels were seen as irrefutable categories for which specific (and often remedial) teaching is required, a highly contested notion (Pantić and Florian, 2015). This then corresponds to low expectations held by the student teachers (but also the school teachers) from those pupils designated as 'low ability':

I would start with a straightforward question to a low ability student, then add an extension question for middle ability students, in other words, different questions are aimed at different abilities. (Group B, student teacher G)

And, a scaffolding pedagogy as part of providing 'extension' opportunities:

For example, if a pupil has SEN or is of low ability then it's going to be difficult to grasp the higher levels of the topics. Is it not better to teach these students some skills that are relevant to science rather than teach them stuff they're never going to use in life? I still try and teach them the same topics... ..., there will be extensions, like the opportunity to achieve higher than their designated ability. (Group A, interviewee H) 
The notion of inclusion as a form of teaching and learning in which a common experience is universally shared was almost entirely absent in student teachers' responses. Only 4 of the student teachers identified potential pitfalls in teaching according to pupil's ability designations. Interestingly, these were Physics and Mathematics students who, because of the nature of their combined programmes of study, had taught the same pupils in both subjects. In their pupil observations they begun to appreciate the contextual nature of attainment and to challenge the notion that ability is a fixed property:

I taught the same pupil science and maths and she only needed help in maths, she didn't need help with maths in her science. A lot of that is down to the teacher....you have to retest her needs to see if they're as bad as described in her paperwork. (Group B, student teacher E)

This comment, whilst relatively isolated, implies that it would be beneficial if student teachers were required to develop a more holistic view of learners with specific characteristics, by following different pupils in different learning environments or coconstructing a learning profile with the individual, where one is not already in existence. In this way a more ecological understanding could be developed and the student teacher could better see the extent to which school structures create or contribute to educational exclusion.

There is a widespread understanding amongst almost all student teachers that differentiation is a marker of inclusive practice, but this raises questions as to what is a valid basis for differentiation and what forms it should take. Of the major mechanisms for differentiation, 'differentiation by support' was mentioned by only three student teachers, one of whom noted that support was not available, in practice. Although different assessment outcomes were central to the responses of student teachers in Group A and Group B, this was not understood to be a form of differentiation. 'Differentiation by outcome' on the other hand, pervaded responses in groups $\mathrm{A}$ and $\mathrm{B}$, being assumed in the repeated causal connections between ability and attainment. Differentiation was commonly described by groups A and B as constituting different tasks according to pre-judged and assigned 'ability' and specified disabilities. We are of course aware that these responses reflect the relative powerlessness of student teachers to change their teaching context, certainly while in school placements. There seemed to be however little doubt or challenge to the practices described here, or the direct connections between ability and how it informs learning potential and hence teaching strategies.

\section{Bridging experiences - the role of teacher education}

Whilst the university and school-based components of the course are intended to be complementary, they are seen by the students as disconnected elements in preparation for inclusion. Students, recognised the role of the university sessions as providing the theoretical frameworks and a notion of 'the ideal' which is embodied in policy and practice (Forlin, 2010). The call for training that enhances teachers' deeper insights into practice has resulted in a range of responses by teacher educators, from independent study tasks, (of the sort given to group C), to more systematic revisions of individual courses. The persistence of the 
implementation gap between theory and practice suggests that further systemic changes were needed if continuity between university and school experience is to be achieved:

The university (course) prepares you for school, an initiation by fire sort of thing. If you don't know what is happening, it would be a culture shock, you would be thinking, 'Why aren't they (pupils) learning? If you know, you can prepare for it and reflect on it. There are going to be so many learning difficulties and so many learning styles, so it's a good opportunity to see them and that can feed back to university. (Group B, student teacher G)

The intimate knowledge of the students by practicing teachers seems to be the main strength of school-based practice, a view very much reflected across all the participants in the focus groups:

Being in school ... you go into staff who know the students, you can draw on their advice. You say, 'I tried this,' and they will say, 'You could try that instead'. I think that being in school, I learnt a lot more, but in university, I learnt approaches and stuff like that - school experience is really more important... (Group B, student teacher C)

Because of the university's position as the body that formally recommends students for Qualified Teacher Status, teacher educators are seen as frontline in enforcing compliance with the Teachers' Standards. Students are aware of course of this status, but there is frustration when it comes to certain topics related particularly to what many of them call 'cultural inclusion' in the teaching of science, and the sort of evidence needed to convince their teachers that have achieved the necessary standard:

The whole idea of cultural inclusion and diversity is a bit of an ambiguous topic, especially when it comes up on the Teachers Standards. Then people are faffing about trying to reach that standard. How do you 'tick off' race? (Group A, interviewee B)

Still, most student teachers saw the school experience to be the most important element of their preparation for inclusion, because it was where they observed the modelling of practical strategies which would prepare them for their future job. They frequently felt this was more useful to them but did not seem to recognise the necessity for critiquing school practice (see also, Walton and Lloyd, 2012). This might be attributed to them being at the early ('survival') phase of their career but this apprenticeship approach leaves the status quo in schools unchallenged. This is something that the students acquire, not only from the official teaching at University, but also from interactions with and observations of their colleagues' practice, something that almost all student teachers raised in their interview or focus group discussion:

Coming here (university) and seeing what other students had done and how they'd slotted diversity in has been really helpful, I think...... It's OK for [name of lecturer] to put it on the presentation and things and say, 'Well, you could do this and you could do that' but actually seeing it in a lesson puts it into more context and gives ideas. (Group A, interviewee K)

Interview and focus group data showed very low levels of student engagement with the Prevent Strategy and with practically incorporating the 'fundamental British values' in their 
teaching, despite considerable course emphasis on the policy. This may be accounted for by the perceived dichotomy of the course into theoretical and practice components (Forlin, 2010). Since the Prevent policy is seen to originate in ideology rather than the reality of the school context, it does not sit readily into the students' schema of the course, other than being required for compliance purposes:

I kind of forgot the fundamental British values because no one mentioned that apart from at university at the beginning. (Group B, student teacher N)

The failure to integrate the Prevent legislation into day-to-day school running is noteworthy. It was beyond the scope of this study to identify possible reasons, but the limited evidence available suggests that it has not been consistent with teacher beliefs about their role as educators. This, reiterates the central role of teachers as potent moderators of policy implementation.

\section{Contradictory policy goals and expectations}

The data revealed a conflict between the wider educational aims of schooling, such as inclusive practice, and curriculum-specific content delivery. The pressures that participants felt to give coverage of curriculum content affected both the social contextualising of science, through the incorporation of Fundamental British values (to be delivered through Social, Moral, Spiritual and Cultural values, SMSC), and inclusive practice. The inflexibility which arises from the pressure to 'deliver' curriculum content also curbed the student teachers' capacity to individualise learning experiences. In this way their capacity to work in inclusive ways was curbed. The lack of time, the pressures of an increasingly strong performativity culture and the fear of being associated with poor pupil attainment outcomes, dominated students' thinking:

Sometimes you feel pressure to get all the science done in the lesson and everything else is thought of as extras that you can put in if you've got enough time. (Group B, student teacher A)

Despite these conflicting pressures, five student teachers in group B had incorporated SMSC and FBV approaches within their science teaching, using examples that they had previously seen modelled during their university-based science sessions. They did not, however, see the use of SMSC as fundamental to the teaching of science, rather as a device to engage pupils who were not interested in the subject matter:

I was interested in the story of Robert Hooke, so was showing how we use his law every day. They said, 'Wow, he did such an important thing and we'd never heard of him.' Then they did extra independent research and reported back to me. (Group B, student teacher $\mathrm{N}$ )

They see SMSC as a sweetener, they are interested but it's not in the exam. SEN and English as Additional Language pupils use it very differently and come up with interesting answers. (Group B, student teacher S)

Many students see using stories about the people who generated scientific knowledge as marginal or irrelevant. The pressure to deliver content, through which their success as student 
teachers is evaluated, has redefined science as simply a body of knowledge and underplay the people and processes through which the knowledge was arrived at.

\section{'Fundamental British values' and inclusion}

In our first study, inclusion was not connected to the issues raised by the Strategy since that had not yet been firmly connected to teacher education. As a result, our research design incorporated its requirements in the follow-up study of Groups B and C. Still, the participants in focus group B, even though they were familiar with the existence of the Strategy, did not appear to have more than a superficial knowledge of it. They did not mention it, other than in passing, and did not see it as central to their own preparation as teachers (see also Revell and Bryan, 2016). This may be attributed to their lack of agency in the enforcement of the Strategy, despite the fact that 18 out of 32 of the answers from group $\mathrm{C}$ viewed Prevent as the responsibility of all staff. The student teachers' approach was rather one of a checklist of acceptable values, which could be put into practice in the classroom. Interestingly, these values were not seen as being in conflict with other values implicit in education, such as individual freedom or the rule of law (Struthers, 2017). This wholesale acceptance was widely evidenced in the assignments submitted by group $\mathrm{C}$. This extract below is typical of most students work:

'FBV should be taught to our students in all schools as it will enable them to develop their self-knowledge, self-esteem and self-confidence. It allows them to distinguish what is right from wrong and to respect the civil and criminal law of England. Teaching them these values also enables students to acquire a broad knowledge of, and respect for, participation in the democratic processes, including respect for the basis on which the law is made and applied in England' (Group C, assignment P)

There was discussion in group B about whether fundamental British values actually needed explicit teaching, or whether demonstrating and enforcing the values within the classroom environment fulfilled the requirement, a view that attracted wide support:

In classroom management, I showed FBV. For example, if someone was talking I would say, 'Sorry, someone's being really disrespectful.' Stuff like that. When I was going through rules 1 would give explanations and that would be like, you should respect people. (Group B, student teacher N)

At my placement, every teacher that saw rubbish in corridors or playing fields would pick this up and put it in the bin, without a thought or hesitating. For me, that proved that the values are embedded and students would learn from being able to see their role models practising what they preach. (Group C, assignment T)

Although a number of authors feel strongly that FBV operates from an anti-inclusion position (Elton-Chalcraft, 2017; Smith, 2016; Struthers, 2017), the majority of students in groups B and $\mathrm{C}$ did not view the two as incompatible. In one case, a respondent even viewed inclusion as synonymous with FBV: 
The only chance that I had to practise FBV, and indeed other teachers have been trying to do, is inclusion. (Group C, assignment B)

The majority of respondents in groups B and C were broadly supportive of Prevent and the inculcation of FBV, or simply accepted it as a matter of compliance with the requirements to qualify as a teacher. The generality and universality of the values included as part of FBV made them feel acceptable:

It is what makes the students and teachers feel they are British or they are studying or working in a safe, fair and civilised environment. (Group C, assignment B)

In my view, these values are fundamental to living in a decent society and they should underpin everything we do. (Group C, assignment C)

However, 8 of the 32 students expressed some reservations in their assignments about framing the values as specifically British instead of liberal human rights:

I believe that the values should be used to not only single out faiths that we see on the news and media but for any faith or group that has a tendency for violence and antisocial behaviour. I believe that the values to be promoted are not just British values but human skills (Group C, assignment R)

The values which are promoted, having them under the guise of 'British values' is only creating further divisions. The values promoted are not 'British' ones but rather universal ones. (Group $\mathrm{C}$, assignment $\mathrm{S}$ )

Beyond discomfort at the exclusivity of the term 'British' when referring to liberal values, only two respondents in group $\mathrm{C}$ indicated a more overtly negative evaluation, including the potential marginalisation of minority groups:

The purpose of education is to support the all-round development of young people. It is not about instilling in them a socio-political dogma based on the majority concept of the time (Group C, assignment A)

These highly critical responses contrasted with the majority position, which was sympathetic to the requirement to teach FBV, seen as compatible with the ethos in schools. Only a very small minority saw the values as overtly in conflict with the promotion of inclusion, which was surprising given the high ethnic diversity of the student teacher population.

\section{Conclusion}

Policies relating to inclusion are known to, and implemented by, student teachers who are initially introduced to them during taught sessions in their teacher education courses. However, the practical implementation of these policies was largely moderated by the observed practice within their placement schools' practices. The influence of schools' practice was observed in the finding that the majority of student teachers shared a deficitbased notion of inclusion, which incorporated strategies for the 'remediation' of individuals with particular characteristics. Moreover, the targeting of such interventions relied upon the 
uncritically used notion of 'ability' and the use of assigned identities within special educational categories. Inclusion was understood as the differentiation of academic input to diverse learners based on the pre-determination of expectations of educational outcomes. A model of inclusion that aspires to optimising learning for all and in all contexts, was not articulated at all, despite the fact that it might provide the means to reconcile apparently contradictory policy pressures.

Different educational policies are inconsistent in focus and are perceived as contradictory by student teachers. Policies that regulate the attainment of teacher qualifications and school inspection were dominant in steering the student teachers' pedagogic decision-making and often presented barriers to full inclusion. These policy frameworks created conditions for student teachers to be strategic during the course of their training. So, the requirement to achieve assessment success dominated both the student teachers' priorities in their own training and in their teaching practice. Inclusion was considered to be a positive concept, but despite the discursive recognition of its significance, student teachers opted for a more 'surface' application in order to fulfil the relevant Teachers' Standards. The need to 'teach to the standards' and 'teach to the test' dominated their thinking about inclusion. Divergent individual responses and more critical approaches to what real inclusion would mean, were largely subordinated to performativity pressures.

This applied also to the responses of the student teachers in relation to the Prevent strategy. It is not seen to be either of practical relevance or of relevance to the improvement of attainment. As such, it was either marginal in the students' thinking or merely 'ticked off' in a rather mechanistic way in various assignments. Nevertheless, it should be noted that in principle the Prevent strategy was understood by the overwhelming majority of students to offer a unifying set of principles that can provide social coherence in school and wider society.

Finally, the apparently contradictory requirements of the various policies impacting upon inclusion leave student teachers unclear about what form inclusion should take in practice whilst they do not have a clear philosophical position from which to critique the different policies. As a result, we observe that most student teachers resolve the conflicting pressures by following school practice unquestioningly. The principled commitment to education inclusion requires a much more flexible and open pedagogic practice in schools, freer from policy parameters that limit the conditions for its development. This is not the case in the current system of teacher education in England, and as a result, inclusion can easily become empty rhetoric instead of a critical concept that has the potential to transform children's lives.

A process of creating a genuinely inclusive school relies on teachers who are prepared to examine the educational and social factors that affect their students' learning, reflect on their practice, and engage with their pupils in all their academic, social and cultural diversity (Allan, 2010; Cochran-Smith, 2004). This requires both an understanding of how pupils learn but also the impact of social contexts on their daily experiences (Florian and Spratt, 2013). These are impeded when policy contexts contribute to the inadvertent perpetuation of disadvantage through limited and attainment-based definitions of inclusive practice. 


\section{References}

Ainscow, M., Dyson, A. and Booth, T. (2006). Improving Schools, Developing Inclusion. Routledge.

Alexiadou, N. (2001). Researching policy implementation: interview data analysis in institutional contexts. International Journal of Social Research Methodology, Theory and Practice, 4(1), 61-61.

Alexiadou, N. and Essex, J. (2016). Teacher education for inclusive practice - Responding to policy. European Journal of Teacher Education, 39(1), 5-19.

Allan, J. (2010). Questions of inclusion in Scotland and Europe. European Journal of Special Needs Education, 25(2), 199-208.

Allday, R.A., Neilsen-Gatti, S. and Hudson, T.M. (2013). Preparation for inclusion in teacher education pre-service curricula. Teacher Education and Special Education, 36 (4), 298-311.

Aronson, J. (1994). A pragmatic view of thematic analysis. The Qualitative Report, 2(1), 1-3.

Artiles, A.J. and Dyson, A. (2005). Inclusive education in the globalization age: The promise of comparative cultural historical analysis. In D. Mitchell (Ed), Contextualizing Inclusive Education. Pp.37-62. London: Routledge.

Ben-Peretz, M. and Flores, A.M. (2018). Tensions and paradoxes in teaching: implications for teacher education. European Journal of Teacher Education, 41(2), 202-213.

Bryman, A. (2016). Social Research Methods. Fifth Edition. Oxford: Oxford University Press.

Cochran-Smith, M. (2004). Walking the Road: Race, Diversity and Social Justice in Teacher Education, Multicultural Education Series. Teachers' College. Columbia University.

DeLuca, C. (2012). Promoting inclusivity through and within teacher education programs. Journal of Education for Teaching, 38(5), 551-569.

Department for Education. (2011). Teachers'Standards. https://assets.publishing.service.gov.uk/government/uploads/system/uploads/attachment data/file/665 522/Teachers_standard information.pdf(Accessed March 2019).

Department for Education. (2014). Promoting fundamental British values as part of SMSC in schools: Departmental advice for maintained schools. Department for Education.

https://assets.publishing.service.gov.uk/government/uploads/system/uploads/attachment data/file/380 595/SMSC_Guidance_Maintained_Schools.pdf_(Accessed March 2019).

Department for Education. (2018). Permanent and Fixed Period Exclusions in England: 2016 to 2017. National Statistics. Department for Education.

https://assets.publishing.service.gov.uk/government/uploads/system/uploads/attachment_data /file/726741/text exc1617.pdf (Accessed March 2019).

Department for Education. (2018b). Schools, Pupils, and their Characteristics, January 2018. National Statistics. Department for Education

(https://lginform.local.gov.uk/reports/Igastandard?mod-metric=2208andmod- 
(Accessed March 2019).

Elton-Chalcraft, S., Lander, V., Revell, L. Warner, D. and Whitcroft, L. (2017). To promote or not to promote Fundamental British Values? Teachers' standards, diversity and teacher education. British Education Research Journal, 43(1), 29- 48.

Essex, J. (2018). Why 'science for all' remains an aspiration: staff views of science for learners with Special Educational Needs and Disabilities. Support for Learning, 33(1), 52-72.

EASNIE (2018) Country Policy Review and Analysis: Methodology Report-Revised 2018. (S. Symeonidou, V.J. Donnelly, V. Soriano and A. Watkins, eds.). European Agency for Special Needs and Inclusive Education. Odense: Denmark.

Equality Act. (2010). Equality Act 2010. United Kingdom. http://www.legislation.gov.uk/ukpga/2010/15 (Accessed March 2019).

Florian, L. and Spratt, J. (2013). Enacting inclusion: a framework for interrogating inclusive practice. European Journal of Special Needs Education, 28(2), 119-135.

Forlin, C. (2010). Teacher education reform for enhancing teachers' preparedness for inclusion. International Journal of Inclusive Education, 14(7), 649-653.

Furlong, J. (2013) Globalisation, Neoliberalism, and the reform of teacher education in England. The Educational Forum, 77(1), 28-50.

Gavish, B. (2017). Four profiles of inclusive supportive teachers: Perceptions of their status and role in implementing inclusion of students with special needs in general classroom. Teaching and Teacher Education, 61, 37-46.

Gay, G. (2010). Culturally responsive teaching: Theory, research, and practice. Teachers College. Columbia University.

Gilroy, P. (2014). Policy interventions in teacher education: sharing the English experience. Journal of Education for Teaching, 40(5), 622-632.

Gomez, M.L. (2007). Seeing our lives intertwined: Teacher education for cultural inclusion. Language Arts, 365-374.

Göransson, K. and Nilholm. C. (2014). Conceptual diversities and empirical shortcomings: A critical analysis of research on inclusive education. European Journal of Special Needs Education, 29(3), 265-280.

Home Office, (2019) Guidance for specified authorities in England and Wales on the duty in the Counter-terrorism and Security Act 2015 to have due regard to the need to prevent people from being drawn into terrorism. 16 July 2015.

https://assets.publishing.service.gov.uk/government/uploads/system/uploads/attachment data /file/445977/3799 Revised Prevent_Duty Guidance England Wales V2-Interactive.pdf. (Accessed March 2019).

Jones, K. (2016). Education in Britain 1944 to the Present. Cambridge: Policy Press. 
Kellner, D. (2003). Towards a critical theory of education. Democracy and Nature, 9(1), 5164.

Lambe, J. and Bones, R. (2007). The effect of school-based practice on student teachers' attitudes towards inclusive education in Northern Ireland. Journal of Education for Teaching, 33(1), 99-113.

Lancaster, J. and Bain, A. (2018). Teacher preparation and the Inclusive practice of preservice teachers: a comparative follow-up study, International Journal of Inclusive Education, DOI: 10.1080/13603116.2018.1523954.

Ofsted (2015). Inspecting initial teacher education: guidance for inspectors. https://assets.publishing.service.gov.uk/government/uploads/system/uploads/attachment data /file/780134/ITE handbook_April_2019 200219.pdf. (Accessed March 2019).

Panjwani, F. (2016). Towards and overlapping consensus: Muslim teachers' views on fundamental British values. Journal of Education for Teaching, 42(3), 329-340.

Pantić, N. and Florian, L. (2015). Developing teachers as agents of change and social justice. Education Inquiry, 6(3), 333-351.

Potter, J., Edwards, D., Wetherell, M. (1993). A model of discourse in action. American Behavioral Scientist. 36, 383-401.

Revell, L. and Bryan, H. (2016). Calibrating fundamental British values: how head-teachers are approaching appraisal in the light of the Teachers' Standards 2012, Prevent and the Counter-Terrorism and Security Act, 2015. Journal of Education for Teaching: International Research and Pedagogy, 42(3), 341-353.

Robinson, D. and Goodey, C. (2018). Agency in the darkness: 'fear of the unknown', learning disability and teacher education for inclusion. International Journal of Inclusive Education, 22(4), 426-440.

Santoro, N. and Forghani-Arani, N. (2015). Interrogating practice in culturally diverse classrooms: What can an analysis of student resistance and teacher response reveal?" European Journal of Teacher Education, 38(1), 58-70.

Schmidt, W.H., Burroughs, N.A., Zoido, P. and Houang, R.T. (2015). The role of schooling in perpetuating educational inequality: An international perspective. Educational Researcher, 44(7), 371-386.

Skidmore, D. (1996). Towards an integrated theoretical framework for research into special educational needs. European Journal of Special Needs Education, 11(1), 33-47.

Smith, H.J. (2016). Britishness as native racism: A case of the unnamed 'other'. Journal of Education for Teaching, 42(3), 298-313.

Smyth, F., Shevlin, M., Buchner, T., Biewer, G., Flynn, P., Latimier, C., Šiška, J., TobosoMartín, M., Rodríguez Díaz, S., and Ferreira, M.A.V. (2014). Inclusive education in 
progress: Policy evolution in four European countries. European Journal of Special Needs Education, 29(4), 433-445.

Sosu, E.M., Mtika, P. and Colucci-Gray, L. (2010). Does initial teacher education make a difference? The impact of teacher preparation on student teachers' attitudes towards educational inclusion, Journal of Education for Teaching, 36(4), 389-405

Struthers, A.E.C. (2017). Teaching British values in our schools: But why not human rights values. Social and Legal Studies, 26(1), pp 89-110.

United Nations Educational, Social and Cultural Organisation (UNESCO). (2009).

Guidelines for Inclusion: Ensuring Access to Education for All. http://unesdoc.unesco.org/images/0014/001402/140224e.pdf (Accessed January 2019).

Valiandes, S. Neophytou, L. and Hajisoteriou, C. (2018). Establishing a framework for blending intercultural education with differentiated instruction. Intercultural Education, 29(3), 379-398.

Villanueva, M.G., Taylor, J., Therrien, W. and Hand, B. (2012). Science education for pupils with special needs. Studies in Science Education, 48(2), 187-215.

Waitoller, F. and Artiles, A. (2013). A decade of professional development research for inclusive education: A literature review and notes for a sociocultural research program. Review of Educational Research, 83, 319-356.

Walton, E. and Lloyd, G. (2012). From clinic to classroom: A model of teacher education for inclusion. Perspectives in Education, 30(2), 62-70.

Young, K.S and Florian, L. (2013). Researching teacher education for inclusion: using a methodological memo. International Journal of Research and Method in Education, 36(4), $355-371$. 